\title{
Development and Validation of Simple RP-HPLC Method for Intracellular Determination of Fluconazole Concentration and Its Application to the Study of Candida albicans Azole Resistance
}

\author{
Tigran K. Davtyan, Levon A. Melikyan, Nune A. Nikoyan, \\ Hripsime P. Aleksanyan, and Nairi G. Grigoryan \\ Scientific Center of Drug and Medical Technology Expertise JSC, Ministry of Health of Armenia, Komitas 49/4, 0051 Yerevan, Armenia \\ Correspondence should be addressed to Tigran K. Davtyan; tigdav@excite.com
}

Received 25 August 2015; Revised 21 October 2015; Accepted 4 November 2015

Academic Editor: Josef Havel

Copyright (C) 2015 Tigran K. Davtyan et al. This is an open access article distributed under the Creative Commons Attribution License, which permits unrestricted use, distribution, and reproduction in any medium, provided the original work is properly cited.

Candida albicans (strains NCTC-885-653 and ATCC-10231) long-term cultivated in the presence of antifungal agent fluconazole (FLC) and classical microbiological methods for determination of minimal inhibitory concentration (MIC) were used in this study. A simple and sensitive method based on reverse-phase high-performance liquid chromatography (RP-HPLC) has been developed for the determination of FLC intracellular concentration in C. albicans using tinidazole as an internal standard. Following extraction with dichloromethane, the chromatographic separation was achieved on a Machery-Nagel EC250/2 Nucleodur-100-3 C18 column by gradient elution using the mobile phase consisting of (A) $0.01 \mathrm{M}$ ammonium acetate buffer, $\mathrm{pH}=5.00$, and (B) acetonitrile. Different analytical performance parameters such as linearity, precision, accuracy, limit of quantification (LOQ), and robustness were determined according to US DHHS FDA and EMEA guidelines. The method was linear for FLC $(r=0.9999)$ ranging from 100 to $10000 \mathrm{ng} / \mathrm{mL}$. The intraday and interday precisions (relative standard deviation) were within 2.79 and 2.64\%, respectively, and the accuracy (relative error) was less than $2.82 \%$. The extraction recovery ranged from 79.3 to $85.5 \%$. The reliable method was successfully applied to C. albicans azole-resistance study and it was shown that intracellular concentration of FLC correlated with a yeast drug susceptibility profile and MIC values.

\section{Introduction}

Acquired drug resistance by microorganisms poses a grave threat to human and animal health and has enormous economic consequences. Fungal pathogens, including the most common opportunistic fungal pathogen C. albicans, represent a particular challenge because they are eukaryotes and share many of the same mechanisms that support the growth and survival of the human host cells they infect. The number of drug classes that have unique targets in fungi is very limited, and the usefulness of current antifungal drugs is compromised by either dose-limiting host toxicity or the frequent emergence of high-grade resistance [1].

Azole compounds represent the most widely used class of antifungal drugs to treat Candida infections [2-4]. Azoles exert their action by inhibiting yeasts enzyme lanosterol $14 \alpha$-demethylase and interfere with the biosynthesis of cell membrane ergosterol which causes inhibition of cell growth and finally cell death [5]. Altered interactions with the target enzyme and altered efflux pump expression are common mechanisms of azole resistance in major Candida species. Resistance can be mediated by increased efflux of azoles resulting from the overexpression of multiple drug resistance genes such as ATP-binding cassette transporters [6].

However, little is known about the mechanisms by which azoles and particularly FLC enter C. albicans. One reason for this is that the inaccessibility of the cytoplasmic face of the plasma membrane precludes direct examination of FLC intracellular transport in intact cells. To circumvent this problem, several groups have studied the ability of 


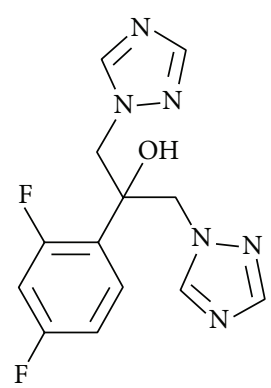

(a)

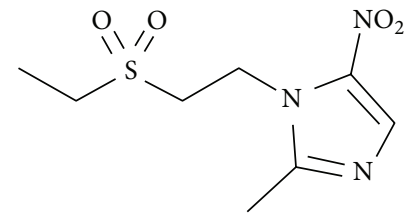

(b)

Figure 1: Chemical structure of fluconazole (a) and tinidazole (b).

C. albicans to pump fluorescent marker compounds out of the cell. These studies have provided important insights into the energetics and kinetics of these pumps, but the fluorescent compounds used in most of these studies are unrelated structurally or functionally to the azole antifungals [7, 8]. Intracellular FLC transport is biochemically characterized by studying cellular accumulation of $\left[{ }^{3} \mathrm{H}\right] \mathrm{FLC}$ [9]. The results suggest that $\left[{ }^{3} \mathrm{H}\right] \mathrm{FLC}$ enters the cell by energy-independent facilitated diffusion and import levels vary among resistant clinical isolates, suggesting that import is a conserved mechanism of resistance to azole drugs in C. albicans [10]. Thus, determination of FLC intracellular concentration in $C$. albicans by sensitive and selective nonradioactive method is a prerequisite not only for understanding drug intracellular transport mechanisms but also for clinical monitoring of azole resistance of C. albicans and other medically important fungi.

A literature survey reveals some HPLC methods that are reported for the determination of FLC in pharmaceutical dosage formulations as anticipated with the variation of mobile phase, column, and detector. Different HPLC methods $[11,12]$ for individual assay are available for FLC in official pharmacopoeia and several LC-MS/MS methods were used for determination of FLC in human plasma [13-15]. Hence, an attempt has been made to develop a simple, efficient, and selective RP-HPLC method for intracellular determination of FLC concentration and its application to azole-resistant $C$. albicans.

\section{Experimental}

2.1. Chemicals and Reagents. FLC (Figure 1(a), USP RS, purity: 99.6\%, batch: HOHO87), tinidazole (Figure 1(b), USP RS, purity: 99.9\%, batch: 0312-QCS-12), ammonium acetate (Sigma-Aldrich, HPLC grade), sodium and potassium chloride and phosphate, millipore water, and methanol (HPLC grade, Alpha Chem Germany, purity: 99.9\%), acetonitrile (HPLC grade, Alpha Chem Germany; purity: 99.9\%), and sodium hydroxide, dichloromethane (Panreac, Spain, 99.9\%) were used in this study.

2.2. Fungal Strains, Culture Media, and Antifungal Drugs. C. albicans NCTC-885-653 and C. albicans ATCC-10231 were purchased from the ATCC (LGC Standards-ATCC). Five different C. albicans clinical isolates have been obtained from Armenicum Clinical Centre (CJSC Armenicum, Yerevan, Armenia). The strains and clinical isolates were cultured in Soya-bean Casein Digest (SBD) medium (HiMedia Laboratories Ltd., India) or Sabouraud Dextrose (SD) agar (Carl Roth, Germany) with aeration at $33^{\circ} \mathrm{C}$. FLC (Diflucan $2 \mathrm{mg} / \mathrm{mL}$ solution for infusion, Pfizer Inc., USA), Amphotericin B (AmB, Amphocil $100 \mathrm{mg}, 50 \mathrm{mg}$ powder for injection, Penn Pharmaceuticals Ltd., UK), and Voriconazole (VRC) substance (Liqvor Pharmaceuticals, Armenia) were used in this study.

2.3. Candida albicans Cultivation and Biological Matrix Preparation. $100 \mathrm{~mL}$ Erlenmeyer flasks in triplicate containing $1 \times 10^{5}$ colony forming units (CFU) of each yeast strain cell in $100 \mathrm{~mL}$ SBD medium were incubated at $33^{\circ} \mathrm{C}$ for $48 \mathrm{~h}$ and yeast growth in SD agar plates at $33^{\circ} \mathrm{C}$ for $48 \mathrm{~h}$ was estimated for every $24 \mathrm{~h}$ by plating of $10 \mu \mathrm{L}$ and $100 \mu \mathrm{L}$ aliquots from the flasks. A total of $1 \times 10^{8} \mathrm{CFU}$ for each yeast strain was harvested and then cells were washed three times in ice cold PBS solution $(137 \mathrm{mmol} / \mathrm{L} \mathrm{NaCl}, 2.7 \mathrm{mmol} / \mathrm{L} \mathrm{KCl}$, $8 \mathrm{mmol} / \mathrm{L} \mathrm{Na}_{2} \mathrm{HPO}_{4}$, and $1.46 \mathrm{mmol} / \mathrm{L} \mathrm{KH}_{2} \mathrm{PO}_{4}$ ) by centrifugation at $3000 \mathrm{rpm}$ at $4^{\circ} \mathrm{C}$ for $15 \mathrm{~min}$. Aliquots of $1000 \mu \mathrm{L}$ samples were stored at $-80^{\circ} \mathrm{C}$ and were brought to room temperature before use for method validation. Equal amounts of C. albicans NCTC-885-653 and ATCC-10231 strains aliquots were mixed and used for blank in biological matrix preparation.

2.4. Chromatographic Conditions. Quantity analysis was acquired by using high-performance liquid chromatography Platin Blue UPLC system (Knauer, Germany) with diode array detector. Nucleodur-100-3 C18 $(250 \times 2 \mathrm{~mm}, 3 \mu \mathrm{m}$ packing, Machery-Nagel, Germany) column and guard column Nucleosil 120-5 C18 (CC 8/4) were employed. Gradient elution was employed using $0.01 \mathrm{~mol} / \mathrm{L}$ ammonium acetate in water $(\mathrm{pH}=5 \pm 0.05$, mobile phase $\mathrm{A})$ and acetonitrile (mobile phase B). The flow rate was set at $0.3 \mathrm{~mL} / \mathrm{min}$ and injection volume was $10 \mu \mathrm{L}$ using a full loop mode for sample injection. The temperatures of column and autosampler were maintained at $30^{\circ} \mathrm{C}$ and $4^{\circ} \mathrm{C}$, respectively. 
2.5. Preparation of Standards and Quality Control Samples. Stock solutions of FLC $(1 \mathrm{mg} / \mathrm{mL})$ and tinidazole used as internal standard (IS, $1 \mathrm{mg} / \mathrm{mL}$ ) were prepared independently by accurately weighing the required amounts into volumetric flasks and dissolving in methanol. The working solutions of FLC were obtained by diluting the stock solution successively with methanol. The stock solution of IS was diluted with solvent using $80: 20(\mathrm{v} / \mathrm{v})(0.01 \mathrm{~mol} / \mathrm{L}$ ammonium acetate buffer : acetonitrile) to make a working solution of $10 \mu \mathrm{g} / \mathrm{mL}$. All solutions were stored at $4^{\circ} \mathrm{C}$ and were brought to room temperature before use. For preparation of standard samples for calibration curve, $50 \mu \mathrm{L}$ of the appropriate working solutions of FLC was added to $1000 \mu \mathrm{L}$ of blank $1 \times 10^{8} \mathrm{CFU}$ C. albicans to prepare concentrations of 100, 200, 500, 1000, 2000, 5000, and $10000 \mathrm{ng} / \mathrm{mL}$ for FLC and $100 \mathrm{ng} / \mathrm{mL}$ for IS. Quality control (QC) samples at three concentration levels (low, $250 \mathrm{ng} / \mathrm{mL}$; medium, $2500 \mathrm{ng} / \mathrm{mL}$; high, $8000 \mathrm{ng} / \mathrm{mL}$ ) were independently prepared in the same way. The standards and QC samples were freshly prepared before use.

2.6. Sample Preparation. A simple liquid-liquid extraction method was applied to extract the analyte and IS from $C$. albicans. Aliquots of $1000 \mu \mathrm{L} 1 \times 10^{8} \mathrm{CFU}$ C. albicans sample were transferred to a $10 \mathrm{~mL}$ polypropylene tube followed by the addition of $50 \mu \mathrm{L}$ IS working standard solution and $25 \mu \mathrm{L}$ of $6 \mathrm{~N} \mathrm{NaOH}$ solution and vortex-mixed for $15 \mathrm{sec}$. $500 \mu \mathrm{L}$ of $0.01 \mathrm{~mol} / \mathrm{L}$ sodium phosphate buffer $(\mathrm{pH}=6.0)$ was added and vortex-mixed for $15 \mathrm{sec}$. Then, the mixture was extracted with $5 \mathrm{~mL}$ dichloromethane by vortex-mixing for $5 \mathrm{~min}$. The supernatant was transferred to another tube after centrifugation at $3000 \mathrm{rpm}$ at $20^{\circ} \mathrm{C}$ for $10 \mathrm{~min}$ and evaporated to dryness at $45^{\circ} \mathrm{C}$ under a gentle stream of nitrogen. Finally, the residue was reconstituted in $100 \mu \mathrm{L}$ of the solvent followed by centrifugation at $3000 \mathrm{rpm}$ at $20^{\circ} \mathrm{C}$ for $5 \mathrm{~min}$. An aliquot of $10 \mu \mathrm{L}$ of the supernatant was injected into the Platin Blue HPLC system in the full loop mode.

2.7. Method Validation. The method was validated for specificity, calibration curve, accuracy, precision, recovery, matrix effect, stability, and dilution effect in C. albicans according to the US Food and Drug Administration guidelines (US DHHS, 2001; European Medicines Agency, 2012) on bioanalytical method validation $[16,17]$.

2.7.1. Specificity. Comparing the chromatograms of blank $1 \times 10^{8} \mathrm{CFU}$ C. albicans, $1 \times 10^{8} \mathrm{CFU}$ C. albicans sample spiked with FLC and IS, and $1 \times 10^{8} \mathrm{CFU} C$. albicans sample after long-term cultivation of yeast cells in the presence of 1/25 MIC $(20 \mu \mathrm{g} / \mathrm{mL})$ of FLC, no endogenous, medium components and metabolites of FLC interfered in the assay of the analyte and IS.

2.7.2. Calibration Curve. The calibration curves were constructed by plotting the peak-area ratios of each analyte to IS versus biological matrix concentrations using a $1 / x^{2}$ weighted least-squares linear regression model. The acceptance criterion for each back-calculated standard concentration was $\pm 15 \%$ deviation from the nominal value, except at the LOQ, which was within $\pm 20 \%$.

2.7.3. Precision and Accuracy. The intraday precision and accuracy were determined by analyzing QC samples at three concentration levels (low, $250 \mathrm{ng} / \mathrm{mL}$; medium, $2500 \mathrm{ng} / \mathrm{mL}$; high, $8000 \mathrm{ng} / \mathrm{mL}$ ) in six replicates on the same day, while the interday precision and accuracy were evaluated by analyzing QC samples at three concentration levels on three continual validation days. The precision was expressed as relative standard deviation (RSD, \%) and the accuracy as the relative error (RE, \%).

2.7.4. Recovery and Matrix Effect. The extraction recoveries of FLC at three QC levels with six replicates were measured by comparing the peak areas from extracted samples with those from postextracted blank C. albicans samples spiked with the analytes at the same concentration. The extraction recovery of IS was evaluated in the same way.

The matrix effect was measured at three QC levels by comparing the peak area from the postextracted blank $C$. albicans spiked with FLC working solutions with those of corresponding standard solutions. The matrix effect of IS was evaluated using the same procedure.

2.7.5. Stability. The stability of FLC in C. albicans was conducted at the two QC concentration levels $(n=5)$ in various storage conditions. Postpreparative stability was evaluated by analyzing the processed QC samples kept in an autosampler at $18^{\circ} \mathrm{C}$ for $48 \mathrm{~h}$. Short-term and long-term stability were studied by analyzing QC samples exposed at room temperature for $4 \mathrm{~h}$ and stored at $-80^{\circ} \mathrm{C}$ for 4 months, respectively. The freeze and thaw stability was tested by analyzing QC samples undergoing three freeze-thaw $\left(-80^{\circ} \mathrm{C}\right.$ to room temperature) cycles on three consecutive days.

2.7.6. Dilution Effect and Carry-Over. Dilution effect was investigated to ensure that samples could be diluted with blank matrix without affecting the final concentration. Blank C. albicans samples spiked with FLC $(16000 \mathrm{ng} / \mathrm{mL})$ were diluted with pooled blank $C$. albicans at dilution factors of 2 in six replicates and analyzed. The six replicates should have precision of $\leq 15 \%$ and accuracy within $\pm 15 \%$. The carryover was determined by injecting a blank $C$. albicans sample following the injection of an upper limit of quantification sample in three independent runs. Carry-over was considered negligible if the measured peak area was $<20 \%$ of the lowest standard area.

2.8. Application to Candida albicans Azole-Resistance Study. This validated method was applied to determine the intracellular FLC concentration in C. albicans NCTC-885-653 and ATCC-10231 strains long-term serially cultivated in the presence of FLC. $5 \times 10^{4} \mathrm{CFU} / \mathrm{mL}$ of cells in the SBD medium was incubated in separate tubes with total volume of $1.0 \mathrm{~mL}$ containing $1 / 25$ of MIC concentration of FLC and incubated at $33^{\circ} \mathrm{C}$ for $48 \mathrm{~h}$ for obtaining one generation. The fungal strains were propagated in the presence or absence of 
selecting antifungal drugs for a total of 20 generations and MIC values for FLC, VRC, and AmB of every fifth generation of each strain were estimated.

$100 \mathrm{~mL}$ Erlenmeyer flasks in triplicate containing 1/25 of MIC concentration of FLC and $1 \times 10^{5} \mathrm{CFU} / \mathrm{mL}$ of each yeast strain (NCTC-885-653 and ATCC-10231) cell at 20th generation in $100 \mathrm{~mL} \mathrm{SBD}$ medium were incubated at $33^{\circ} \mathrm{C}$ for $48 \mathrm{~h}$ and yeast growth in SD agar plates at $33^{\circ} \mathrm{C}$ for $48 \mathrm{~h}$ was estimated for every $24 \mathrm{~h}$ by plating of $10 \mu \mathrm{L}$ and $100 \mu \mathrm{L}$ aliquots from the flasks. A total of $1 \times 10^{8} \mathrm{CFU}$ yeast cells were harvested and biological matrix was prepared as described above.

For determination of the FLC intracellular concentration in C. albicans NCTC-885-653 and ATCC-10231 strains and 5 different $C$. albicans clinical isolates $1 \times 10^{6} \mathrm{CFU} / \mathrm{mL}$ of each yeast strain in $100 \mathrm{~mL} \mathrm{SBD}$ medium were incubated at $33^{\circ} \mathrm{C}$ for $30 \mathrm{~min}$ in triplicate containing $20 \mu \mathrm{g} / \mathrm{mL}$ concentration of FLC and a total of $1 \times 10^{8} \mathrm{CFU}$ yeast cells were harvested for biological matrix preparation.

2.8.1. Determination of Minimal Inhibitory Concentration $(M I C)$. Fungal strains were grown in $\mathrm{SD}$ agar at $33^{\circ} \mathrm{C}$ for 48. One colony was inoculated in $5 \mathrm{~mL}$ of SBD medium and washed twice with $0.9 \% \mathrm{NaCl}$ and the fungal count was determined by spotting on SD agar. The initial concentration of the fungal suspension in the SBD medium was $5 \times 10^{4} \mathrm{CFU} / \mathrm{mL}$. $0.5 \mathrm{~mL}$ of suspension was inoculated into separate tubes containing serial twofold dilutions of antifungal drugs. Azole antifungal drugs (FLC and VRC) dissolved in distilled water and tested in the range of 0.95 to $1000 \mu \mathrm{g} / \mathrm{mL}$ and $\mathrm{AmB}$ in the range of 0.0078 to $2 \mu \mathrm{g} / \mathrm{mL}$ of serially diluted drugs were added to the tubes, yielding a total volume of $1 \mathrm{~mL}$ per tube. Drug-free medium with fungi and a fungi-free medium were used as the positive and negative controls, respectively. After incubation at $33^{\circ} \mathrm{C}$ for $48 \mathrm{~h}$, the results were read visually, as recommended by the Clinical and Laboratory Standards Institute [18]. The MIC was considered to be the concentration that inhibited $100 \%$ of fungal growth. MIC values were confirmed by plating of $10 \mu \mathrm{L}$ and $100 \mu \mathrm{L}$ aliquots from the tubes with visual lack of growth on SD agar [19]. C. parapsilosis ATCC-22019 were included in each susceptibility test for quality control and assessment of reproducibility testing. Each assay was performed in triplicate on three different days.

\section{Results and Discussion}

3.1. Method Development. The aim of this study was to develop a simple, efficient, and selective RP-HPLC method for intracellular determination of FLC concentration in C. albicans. Various attempts were made to separate both the analyte and IS with different $\mathrm{pH}$ of the mobile phase buffer and composition of methanol in the mobile phase using C-18 and C-8 stationary phase columns. To ensure great resolution between known and unknown endogenous compounds, the C-18 stationary phase with an endcapping was used. Tinidazole (Figure 1(b)) was selected as the IS since its structure, chromatographic behavior, and extraction efficiency were similar to those of the analyte. HPLC parameters, such as detection wavelength, ideal mobile phase, and their proportions and flow rate, were carefully studied. After trying different ratios of mixtures of acetonitrile and ammonium acetate buffer, the best results were achieved by using gradient elution. Both the analyte and IS displayed the best intensity and peak shape in the mobile phase containing $80: 20(\mathrm{v} / \mathrm{v}) \quad 0.01 \mathrm{M}$ ammonium acetate (solvent $\mathrm{A}$ ) and acetonitrile (solvent $\mathrm{B}$ ).

\subsection{Method Validation}

3.2.1. Specificity and Selectivity. At a flow rate of $0.3 \mathrm{~mL} / \mathrm{min}$ and the detection wavelength $210 \mathrm{~nm}$, the retention time was $6.8 \pm 0.02 \mathrm{~min}$ for FLC and $5.6 \pm 0.01 \mathrm{~min}(P<0.0001)$ for IS. The analytes peak areas were well defined and free from tailing under the described experimental conditions (Figure 2). Typical chromatograms of FLC in C. albicans are shown in Figure 2. Blank chromatograms with UV spectra of unidentified compounds from C. albicans biomass are represented in Figure 3. Obviously, there were no significant interferences from endogenous substances and metabolites of FLC at the retention time of FLC and IS.

3.2.2. Calibration Curve. Calibration curve showed a satisfactory linearity in the range of $100-10000 \mathrm{ng} / \mathrm{mL}$. A typical calibration curve equation was $y=0.022 x+3.542$, with correlation coefficient of 0.9999 , where $y$ is the peak-area ratio of FLC to IS and $x$ is the nominal concentration of FLC. The deviations of the back-calculated concentrations from their nominal values of LOQ ranged from -1.75 to $2.07 \%$ and standards other than LOQ were within -2.02 to $3.84 \%$.

3.2.3. Precision and Accuracy. The intra- and interday precision and accuracy at corresponding QC levels are summarized in Table 1 . The results indicated that the method showed good precision and accuracy.

3.2.4. Recovery and Matrix Effect. The extraction recoveries of FLC at the three QC levels were 79.3, 78.6, and 85.5\%, respectively. The recovery of IS $(100 \mathrm{ng} / \mathrm{mL})$ was $89.4 \%$. The extract recovery of all analytes was constant, precise, and reproducible with average percentage extraction recoveries of FLC $81 \pm 4 \%$ (RSD\%: 4.7). The matrix effects of FLC and IS were in the range of $85.7-90.2 \%$, which meant that there was no significant retention time suppression or enhancement for FLC and IS.

3.2.5. Stability. The stability data for FLC are presented in Table 2. The result indicated that FLC was stable under the conditions examined.

3.2.6. Dilution Effect and Carry-Over. Diluted QC samples $(16000 \mathrm{ng} / \mathrm{mL})$ with six replicates were determined after dilution to the concentration of $8000 \mathrm{ng} / \mathrm{mL}$, and the results of the tested samples were within the acceptable criteria. No carry-over was observed in the analysis of a blank plasma 


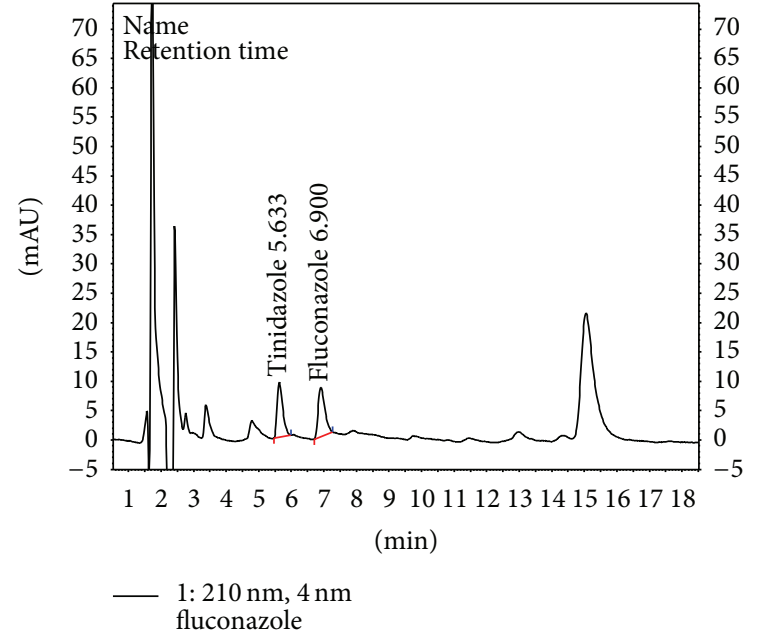

(a)

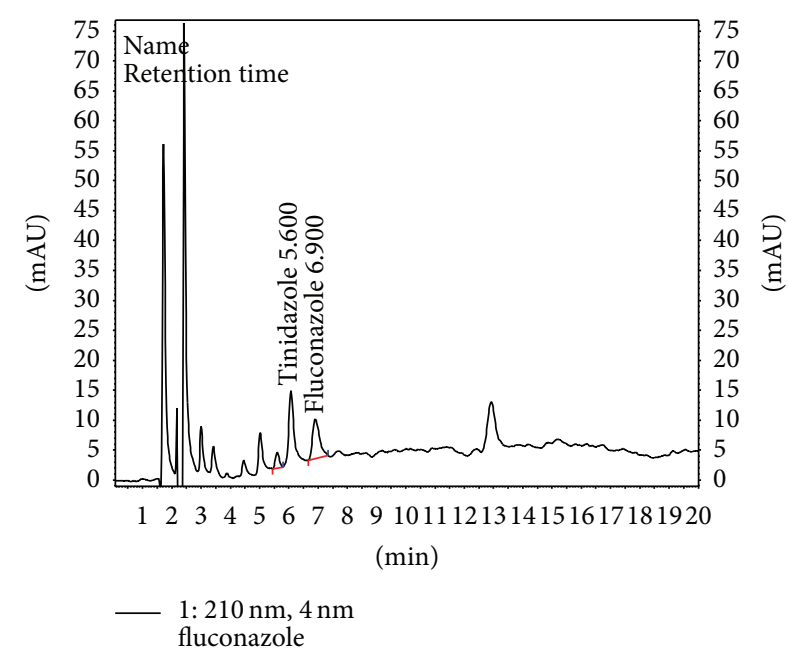

(b)

FIGURE 2: Typical chromatogram of IS and FLC (250 ng/mL) from extracted samples of blank C. albicans (a). Chromatographic separation of IS and FLC in C. albicans ATCC-10231 samples long-term cultivated in the presence of FLC.

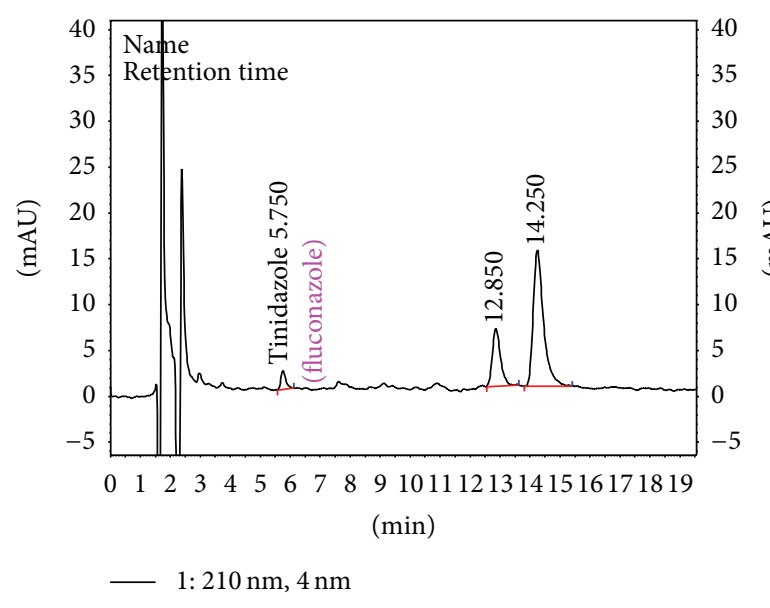

(a)

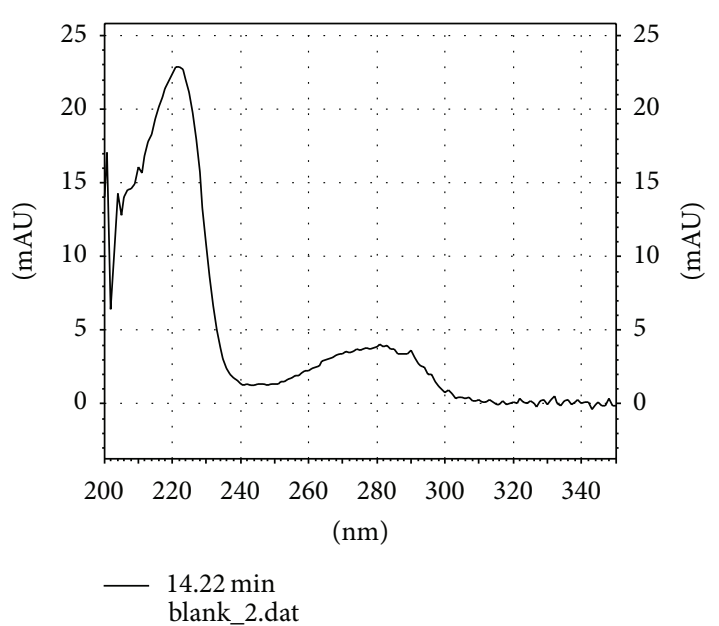

(b)

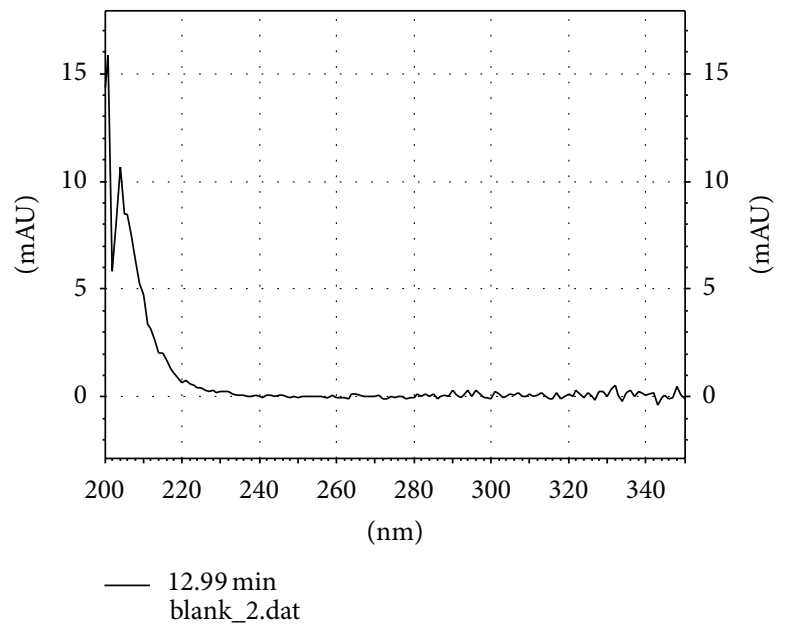

(c)

FIGURE 3: Typical chromatogram of fungi biomass blank with IS tinidazole (a). UV spectra of peak with RT at approximately 13 min (b) and UV spectra of peak with RT at approximately $15 \mathrm{~min}$ (c). 
TABLE 1: Intraday and interday precision and accuracy data for FLC assay in C. albicans matrix.

\begin{tabular}{lcccc}
\hline $\begin{array}{l}\text { Concentration of analyte } \\
\text { added }(\mathrm{ng} / \mathrm{mL})\end{array}$ & $\begin{array}{c}\text { Concentration of analyte } \\
\text { found }(\mathrm{ng} / \mathrm{mL})^{*}\end{array}$ & $\begin{array}{c}\text { Intraday } \\
(\mathrm{RSD}, \%)^{9}\end{array}$ & $\begin{array}{c}\text { Interday } \\
(\mathrm{RSD}, \%)^{9}\end{array}$ & $\begin{array}{c}\text { Relative error } \\
(\mathrm{RE}, \%)^{\circ}\end{array}$ \\
\hline 250 & $252 \pm 7$ & 2.79 & 2.64 & 0.68 \\
2500 & $2571 \pm 61$ & 2.35 & 2.99 & 2.82 \\
8000 & $8038 \pm 59$ & 0.73 & 1.05 & 0.47 \\
\hline
\end{tabular}

${ }^{*}$ Mean and SD representation for $n=10$ standard samples for each of the mentioned analytes. ${ }^{\boldsymbol{g}} \mathrm{RSD}, \%=100 \times(\mathrm{SD} / \mathrm{mean}) .{ }^{\bullet} \mathrm{RE}, \%=(E-T) \times(100 / T)$, where $E$ is the calculated concentration and $T$ is the introduced concentration of the analyte.

TABLE 2: Stability of FLC assay in C. albicans biological matrix.

\begin{tabular}{|c|c|c|c|c|}
\hline $\begin{array}{l}\text { Nominal concentration } \\
(\mathrm{ng} / \mathrm{mL})\end{array}$ & Room temperature for $4 \mathrm{~h}$ & $\begin{array}{c}\text { Stored at }-80^{\circ} \mathrm{C} \text { for } 4 \\
\text { months }\end{array}$ & $\begin{array}{l}\text { Three freeze and thaw } \\
\text { cycles }\end{array}$ & $\begin{array}{c}\text { Autosampler at } 18^{\circ} \mathrm{C} \\
\text { for } 48 \mathrm{~h} \\
\end{array}$ \\
\hline \multicolumn{5}{|l|}{250} \\
\hline Mean \pm SD & $249 \pm 7$ & $254 \pm 7$ & $234 \pm 4$ & $236 \pm 4$ \\
\hline RSD, \% & 2.7 & 2.82 & 1.8 & 1.6 \\
\hline $\mathrm{RE}, \%$ & -0.24 & 1.6 & -6.32 & -5.68 \\
\hline QC-S/QC-R, \%* & 99.76 & 99.82 & 103.84 & 103.40 \\
\hline \multicolumn{5}{|l|}{8000} \\
\hline Mean \pm SD & $8041 \pm 70$ & $8035 \pm 55$ & $8166 \pm 35.38$ & $8162 \pm 86$ \\
\hline RSD, \% & 0.68 & 0.86 & 0.31 & 1.05 \\
\hline RE, \% & 0.44 & 0.51 & 2.08 & 2.02 \\
\hline QC-S/QC-R, \%* & 99.92 & 99.91 & 102.50 & 100.58 \\
\hline
\end{tabular}

Mean and SD representation for $n=5$ standard samples for each of the mentioned analytes. ${ }^{*}$ QC-S/QC-R, \%: QC-S, samples exposed at room temperature for $4 \mathrm{~h}$ or stored at $-80^{\circ} \mathrm{C}$ for 4 months or undergoing three freeze-thaw cycles or kept in an autosampler at $18^{\circ} \mathrm{C}$ for $48 \mathrm{~h}$, and QC-R, reference samples, respectively.

sample after injection the analysis of the upper calibrator $(10000 \mathrm{ng} / \mathrm{mL})$, which indicated that the carry-over effect was negligible.

3.3. Application to Candida albicans Azole-Resistance Study. This validated method was applied to determine the intracellular FLC concentration in two different C. albicans strains (NCTC-885-653 and ATCC-10231) long-term cultivated in the presence of FLC. The initial susceptibility profile of the selected fungal strains was investigated by determination of MIC values for antifungal drugs FLC, VRC, and AmB (Table 3). The selected C. albicans NCTC-885-653 strain displayed high-level azole resistance as shown by $100 \%$ fungal growth inhibition in the presence of $500 \mu \mathrm{g} / \mathrm{mL}$ concentration of FLC and $62.5 \mu \mathrm{g} / \mathrm{mL}$ concentration of VRC, respectively. In contrast to this strain, C. albicans ATCC-10231 displayed approximately 2-fold low-level azole resistance as MIC values for FLC and VRC were found to be $250 \mu \mathrm{g} / \mathrm{mL}$ and $15.6 \mu \mathrm{g} / \mathrm{mL}$, respectively. However, initial susceptibility profile of the selected fungal strains to nonazole antifungal AmB was found to be identical $(0.25 \mu \mathrm{g} / \mathrm{mL}$, Table 3$)$. Resistance to azole drugs was experimentally induced in the selected fungal strains by long-term serial cultivation (for a total of 20 generations) of fungal cells in the presence of 1/25 of MIC concentration of FLC. The development of azole resistance was achieved for initial azole susceptible C. albicans ATCC-10231 strain in approximately 20 days, and the strain at 20 th generation was resistant to $750 \mu \mathrm{g} / \mathrm{mL}$ concentration of FLC and $500 \mu \mathrm{g} / \mathrm{mL}$ concentration of VRC, respectively,
TABLE 3: MIC* values $(\mu \mathrm{g} / \mathrm{mL})$ for antifungal drugs FLC, VRC, and AmB of C. albicans initial andazole-resistantstrains, cultivated for 20 generations in the presence of FLC'.

\begin{tabular}{lcc}
\hline $\begin{array}{l}\text { Fungal strain/antifungal } \\
\text { drug }\end{array}$ & $\begin{array}{c}\text { C. albicans } \\
\text { NCTC-885-653 }\end{array}$ & $\begin{array}{c}\text { C. albicans } \\
\text { ATCC-10231 }\end{array}$ \\
\hline $\begin{array}{l}\text { Initial strain } \\
\text { FLC }\end{array}$ & 500 & 250 \\
VRC & 62.5 & 15.6 \\
AmB & 0.25 & 0.25 \\
20th generation of & & \\
FLC-resistant strain & & \\
FLC & 500 & 750 \\
VRC & 250 & 500 \\
AmB & 0.125 & 0.500 \\
\hline
\end{tabular}

${ }^{*}$ The MIC was considered to be the concentration of drug that inhibited $100 \%$ of fungal growth. 'The fungal strains were propagated in the presence or absence of $1 / 25$ of MIC concentration of FLC for a total of 20 generations and MIC value for FLC and VRC of each strain.

and also displayed high resistance to AmB (Table 3). The susceptibility profile of the C. albicans NCTC-885-653 strain at 20th generation also displayed high-level azole resistance; however, MIC values for FLC and VRC were found to be $500 \mu \mathrm{g} / \mathrm{mL}$ and $250 \mu \mathrm{g} / \mathrm{mL}$, respectively, and approximately 4-fold low-level AmB resistance (Table 3).

The mean intracellular concentrations of FLC for these two C. albicans strains long-term cultivated in the presence or 


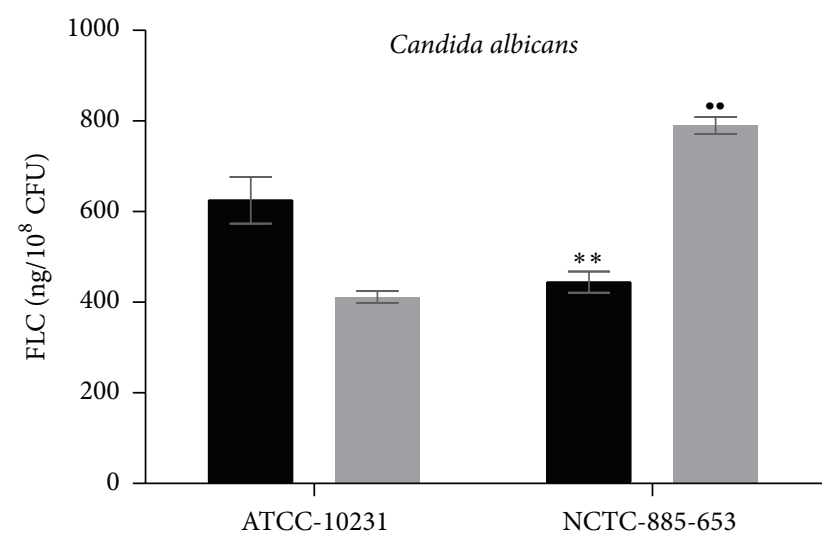

Initial

20th generation

FIGURE 4: Intracellular concentrations of FLC for two different $C$. albicans strains long-term cultivated in the presence or absence of FLC. All data represent mean \pm SD (error bars) for $n=12$, for each fungal culture, and are significantly different comparing initial Candida albicans NCTC-885-653 and Candida albicans ATCC-10231 strains at ${ }^{* *} P<0.003$ and comparing 20th generation of Candida albicans NCTC-885-653 and Candida albicans ATCC-10231 strains at ${ }^{*} P<0.005$, respectively.

absence of FLC are shown in Figure 4. The results indicated that the intracellular concentration of FLC for initially 2fold low-level azole-resistant C. albicans ATCC-10231 is statistically significantly higher comparing with the intracellular concentration of FLC for initially high-level azole-resistant $C$. albicans NCTC-885-653 (625 $\pm 51 \mathrm{ng} / 10^{8} \mathrm{CFU}$ versus $445 \pm$ 24 ng $/ 10^{8} \mathrm{CFU}, P<0.003$, resp.). The intracellular concentration of FLC for high-level azole-resistant C. albicans ATCC10231 at 20th generation displayed 1.5-fold high resistance to antifungal action of FLC, which was found to be statistically significantly lower comparing with that of another high-level azole-resistant C. albicans NCTC-885-653 with 1.5-fold lower MIC value to FLC at 20th generation $\left(412 \pm 50 \mathrm{ng} / 10^{8} \mathrm{CFU}\right.$ versus $790 \pm 74 \mathrm{ng} / 10^{8} \mathrm{CFU}, P<0.005$, resp.). FLC uptake calculation by yeast cell indicated that single CFU of highlevel azole-resistant C. albicans accumulated 8.1-8.7 $\times 10^{6}$ FLC molecules while low-level azole-resistant $C$. albicans accumulated $12.3-15.5 \times 10^{6}$ FLC molecules, which is highly correlated with the 1.5-2.0-fold differences between azole susceptibility profiles of the studied fungal strains.

For future confirmation that the intracellular concentration of FLC reverse-correlated with the azole-resistance profile of fungi, we compared the MIC values and fungal FLC concentration in azole-resistant NCTC-885-653 and ATCC10231 strains at 20th generation with five different $C$. albicans clinical isolates. For this purpose, yeast cells were propagated in the presence of $20 \mu \mathrm{g} / \mathrm{mL}$ concentration of FLC for a total of $30 \mathrm{~min}$ incubation time (during which no significant difference has been observed in yeast cells survival between different strains, data not shown) and FLC intracellular concentration was determined for each strain (Table 4). The results indicated that the intracellular concentrations of
TABLE 4: MIC values for FLC and FLC intracellular concentration $(\mu \mathrm{g} / \mathrm{mL})$ of $C$. albicans azole-resistant strains and five different $C$. albicans clinical isolates".

\begin{tabular}{lcc}
\hline Fungal strains & MIC for FLC & $\begin{array}{c}\text { FLC } \\
\text { intracellular } \\
\text { concentration }\end{array}$ \\
\hline $\begin{array}{l}\text { C. albicans clinical isolates } \\
\quad \text { Number 1 }\end{array}$ & 7.81 & $13 \pm 1^{\cdots *}$ \\
$\quad$ Number 2 & 31.25 & $4 \pm 0.2^{* *}$ \\
Number 3 & 31.25 & $4 \pm 0.2^{* *}$ \\
Number 4 & 62.50 & $10 \pm 1$ \\
$\quad$ Number 5 & 62.50 & $7 \pm 0.4$ \\
C. albicans azole-resistant & & \\
strains & & $0.6 \pm 0.01^{* * *}$ \\
$\quad$ NCTC-885-653 & 500 & $0.3 \pm 0.02^{* * *}$ \\
$\quad$ ATCC-10231 & 750 &
\end{tabular}

${ }^{9} \mathrm{C}$. albicans azole-resistant NCTC-885-653 and ATCC-10231 strains at 20th generation and five different $C$. albicans clinical isolates strains were propagated in the presence of $20 \mu \mathrm{g} / \mathrm{mL}$ concentration of FLC for a total of 30 min and FLC intracellular concentration was determined for each strain. The MIC was considered to be the concentration of FLC that inhibited 100\% of fungal growth during $48 \mathrm{~h}$ incubation time. All data represent mean \pm SD for $n=6$, for each fungal culture, and are significantly different comparing C. albicans NCTC-885-653 and ATCC-10231 strains with clinical isolate at ${ }^{* * *} P<0.0001$ and comparing C. albicans clinical isolate number 1 with numbers $2-5$ at $\cdots P<0.0005$ and clinical isolates number 2 and number 3 with isolates number 4 and number 5 at ${ }^{*} P<0.003$, respectively.

FLC in azole-resistant C. albicans ATCC-10231 and NCTC$885-653$ strains (MIC values in the $500-750 \mu \mathrm{g} / \mathrm{mL}$ range) are statistically significantly lower, comparing with that of azole-susceptible (MIC values in the $7.8-62.5 \mu \mathrm{g} / \mathrm{mL}$ range) C. albicans clinical isolates. The intracellular concentration of FLC for high-level azole-susceptible C. albicans clinical isolate number 1 (displayed 4-fold low resistance to FLC, comparing with isolates numbers 2-5) was found to be statistically significantly higher comparing with the rest of the azole-susceptible clinical isolates, and FLC uptake by 2 -fold low resistance isolates number 2 and number 3 was statistically significantly higher, comparing with that of isolates number 4 and number 5 . Thus, the obtained results clearly demonstrated that FLC uptake by yeast cell is highly correlated with the azole susceptibility profile of the studied fungal strains.

\section{Conclusion}

In the present study, a simple, sensitive, and selective RPHPLC method for intracellular determination of fluconazole concentration in C. albicans was developed for the first time. A relatively simple sample preparation procedure showed greater simplicity. Baseline separation between FLC and IS ensured the accuracy of determination. The method was successfully applied to the determination of FLC intracellular concentration in different azole-resistant C. albicans strains for the first time and will be useful for further characterization of FLC intracellular transport mechanisms and 
for monitoring of drug resistance of $C$. albicans and other medically important fungi.

\section{Conflict of Interests}

The authors declare that there is no conflict of interests regarding the publication of this paper.

\section{Acknowledgment}

The authors thank Professor Hakob V. Topchyan Ph.D., DSc, Director of Scientific Center of Drug and Medical Technology Expertise JSC, Ministry of Health of Armenia, for his critical reading of the paper and support of this study in the centre.

\section{References}

[1] G. Quindós, "Epidemiology of candidaemia and invasive candidiasis. A changing face," Revista Iberoamericana de Micología, vol. 31, no. 1, pp. 42-48, 2014.

[2] R. Franz, S. L. Kelly, D. C. Lamb, D. E. Kelly, M. Ruhnke, and J. Morschhäuser, "Multiple molecular mechanisms contribute to a stepwise development of fluconazole resistance in clinical Candida albicans strains," Antimicrobial Agents and Chemotherapy, vol. 42, no. 12, pp. 3065-3072, 1998.

[3] C. Garcia-Cuesta, M. G. Sarrion-Pérez, and J. V. Bagán, “Current treatment of oral candidiasis: a literature review," Journal of Clinical and Experimental Dentistry, vol. 6, no. 5, pp. e576e582, 2014.

[4] M. C. Arendrup, "Candida and candidaemia. Susceptibility and epidemiology," Danish Medical Journal, vol. 60, no. 11, Article ID B4698, pp. 1-32, 2013.

[5] L. A. Vale-Silva, A. T. Coste, F. Ischer et al., "Azole resistance by loss of function of the sterol $\Delta^{5,6}$-desaturase gene (ERG3) in Candida albicans does not necessarily decrease virulence," Antimicrobial Agents and Chemotherapy, vol. 56, no. 4, pp. 19601968, 2012.

[6] T. C. White, K. A. Marr, and R. A. Bowden, "Clinical, cellular, and molecular factors that contribute to antifungal drug resistance," Clinical Microbiology Reviews, vol. 11, no. 2, pp. 382-402, 1998.

[7] M. de Micheli, J. Bille, C. Schueller, and D. Sanglard, "A common drug-responsive element mediates the upregulation of the Candida albicans ABC transporters CDR1 and CDR2, two genes involved in antifungal drug resistance," Molecular Microbiology, vol. 43, no. 5, pp. 1197-1214, 2002.

[8] C.-G. Chen, Y.-L. Yang, K.-Y. Tseng et al., "Replp negatively regulating MDR1 efflux pump involved in drug resistance in Candida albicans," Fungal Genetics and Biology, vol. 46, no. 9, pp. 714-720, 2009.

[9] L. R. Basso Jr., C. E. Gast, Y. Mao, and B. Wong, "Fluconazole transport into Candida albicans secretory vesicles by the membrane proteins Cdr1p, Cdr2p, and Mdrlp," Eukaryotic Cell, vol. 9, no. 6, pp. 960-970, 2010.

[10] B. E. Mansfield, H. N. Oltean, B. G. Oliver et al., "Azole drugs are imported by facilitated diffusion in Candida albicans and other pathogenic fungi," PLoS Pathogens, vol. 6, no. 9, Article ID e1001126, 2010.

[11] J. C. R. Corrêa, C. D. Vianna-Soares, and H. R. N. Salgado, "Development and validation of dissolution test for fluconazole capsules by hplc and derivative UV spectrophotometry," Chromatography Research International, vol. 2012, Article ID 610427, 8 pages, 2012.

[12] J. C. R. Corrêa and H. R. N. Salgado, "Review of fluconazole properties and analytical methods for its determination," Critical Reviews in Analytical Chemistry, vol. 41, no. 2, pp. 124-132, 2011.

[13] D. Miron, A. Lange, A. R. Zimmer, P. Mayorga, and E. E. S. Schapoval, "HPLC-DAD for the determination of three different classes of antifungals: method characterization, statistical approach, and application to a permeation study," Biomedical Chromatography, vol. 28, no. 12, pp. 1728-1737, 2014.

[14] F. Belal, M. K. Sharaf El-Din, M. I. Eid, and R. M. ElGamal, "Micellar HPLC and derivative spectrophotometric methods for the simultaneous determination of fluconazole and tinidazole in pharmaceuticals and biological fluids," Journal of Chromatographic Science, vol. 52, no. 4, pp. 298-309, 2014.

[15] J.-J. Song, W. Li, Z. Wang, D.-D. Tian, and W.-Y. Yin, “Quantitative determination of fluconazole by ultra-performance liquid chromatography tandem mass spectrometry (UPLC-MS/MS) in human plasma and its application to a pharmacokinetic study," Drug Research, vol. 65, no. 1, pp. 52-56, 2015.

[16] European Medicines Agency, "Guideline on Bioanalytical Method Validation," EMEA/CHMP/EWP/192217/2009, 2012, http://www.ema.europa.eu/docs/en_GB/document_library/Scientific_guideline/2011/08/WC500109686.pdf.

[17] Clinical and Laboratory Standards Institute, "Methods for dilution antimicrobial susceptibility tests for bacteria that grow aerobically; approved standard-ninth edition," CLSI Document M07-A9, Clinical and Laboratory Standards Institute, Wayne, Pa, USA, 2012.

[18] US DHHS, FDA, and CDER, Guidance for Industry, Bioanalytical Method Validation, US Department of Health and Rat Services, Food and Drug Administration, Center for Drug Evaluation and Research, Center for Veterinary Medicine, Rockville, Md, USA, 2001.

[19] I. Vandenbossche, M. Vaneechoutte, M. Vandevenne, T. De Baere, and G. Verschraegen, "Susceptibility testing of fluconazole by the NCCLS broth macrodilution method, E-test, and disk diffusion for application in the routine laboratory," Journal of Clinical Microbiology, vol. 40, no. 3, pp. 918-921, 2002. 

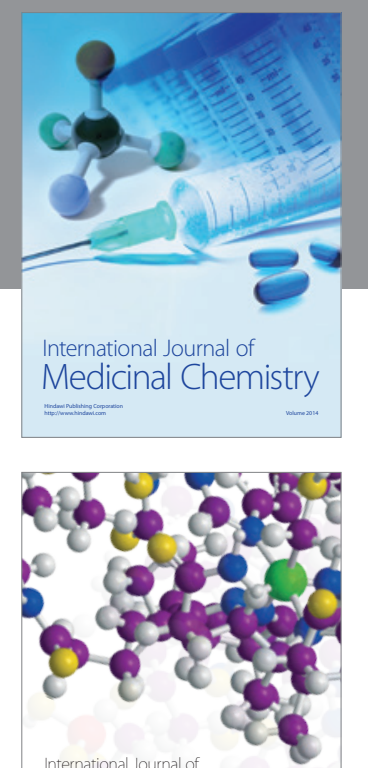

\section{Carbohydrate} Chemistry

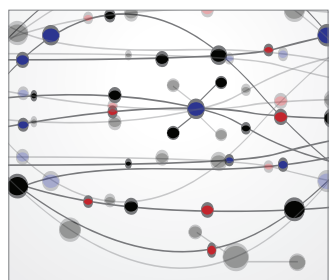

The Scientific World Journal
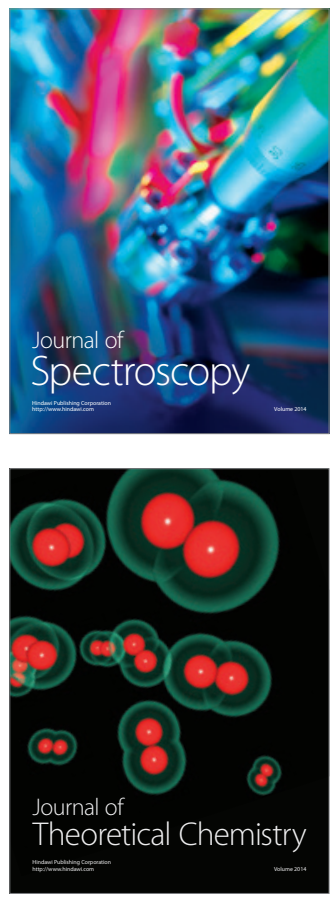
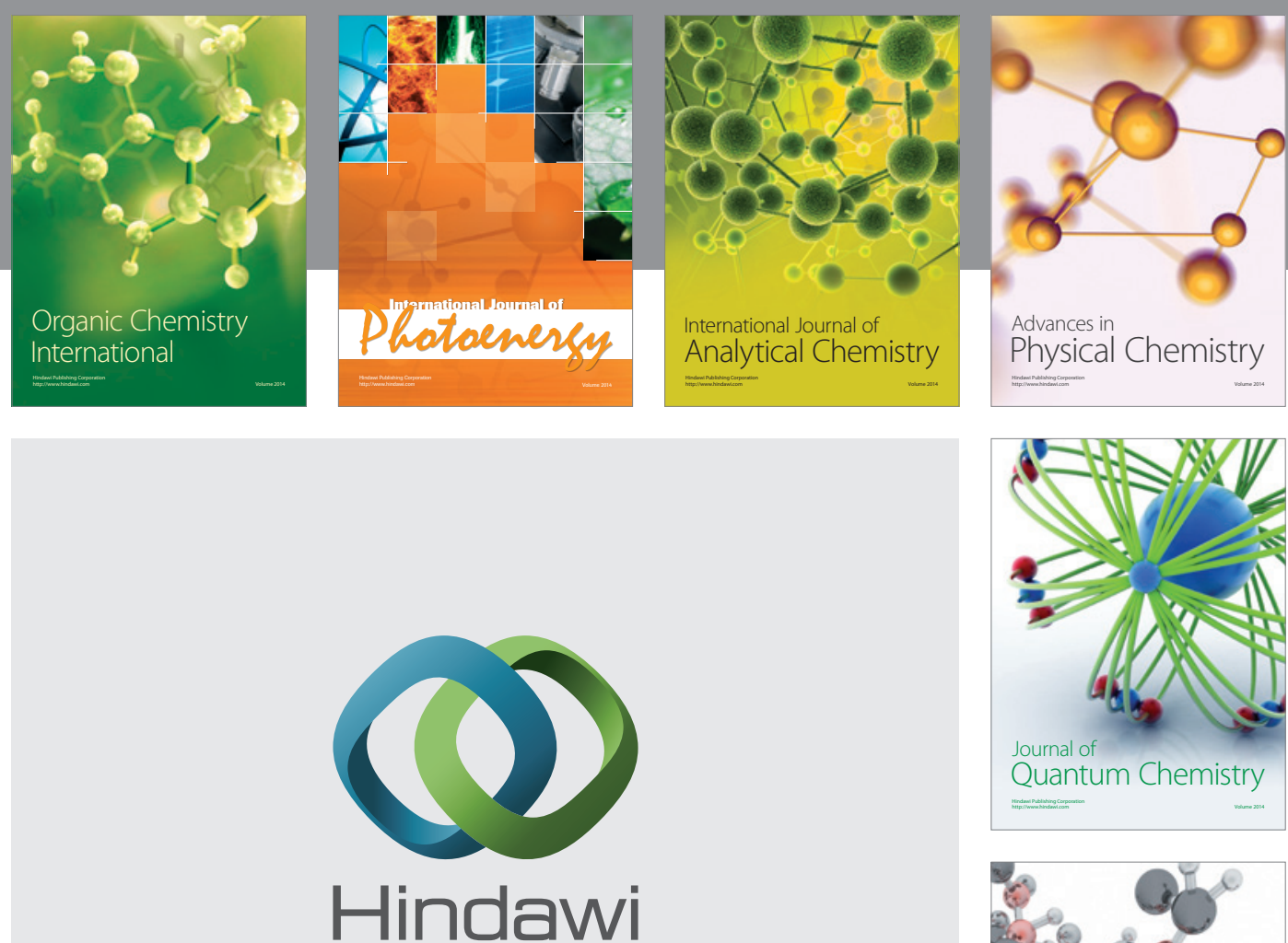

Submit your manuscripts at

http://www.hindawi.com

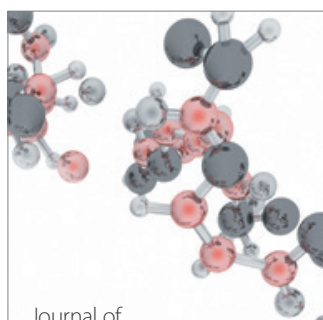

Analytical Methods

in Chemistry

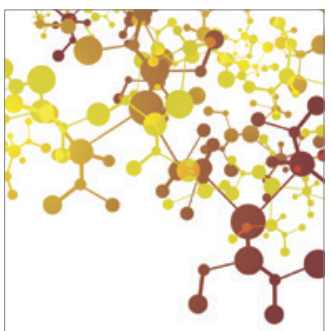

Journal of

Applied Chemistry

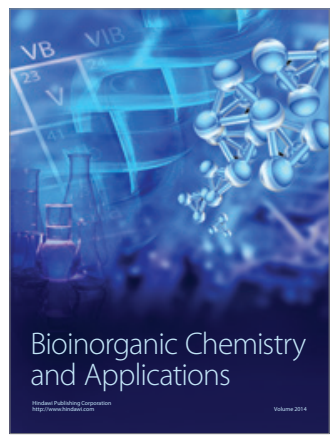

Inorganic Chemistry
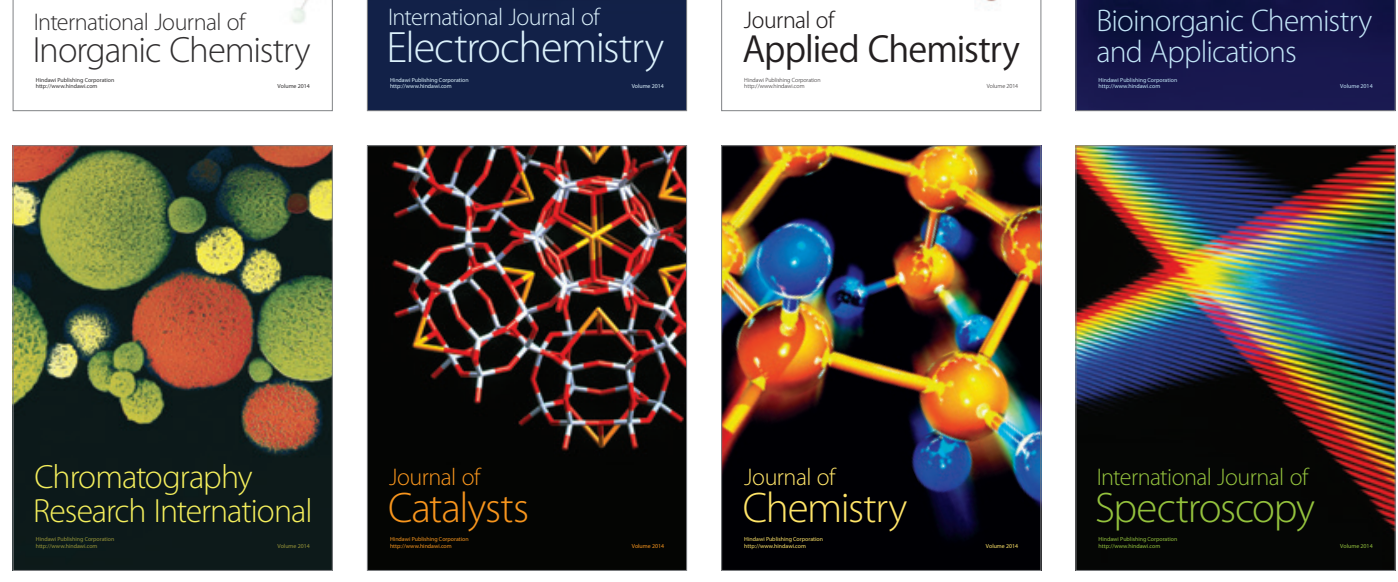